\title{
ARBUSCULAR MYCORRHIZAL ASSOCIATION IN SOME SELECTED DRY FOREST SPECIES AT BUNDALA NATIONAL PARK, SRI LANKA
}

\author{
R A S W Ranasinghe, and G.A.D. Perera \\ Department of Botany, University of Peradeniya
}

The vegetation of dry forests at Bundala National Park, Sri Lanka is under a threat due to the invasion of alien exotic species and poor natural forest regeneration. Since it is important to understand the effects of soil microorganisms in sustainable forest management, this study attempts to find out how the mycorrhizal infections would favour dry forest plant species for their growth and survival. Fine lateral roots of seven natural forest species (Cassia auriculata, Drypetes sepiaria, Dichrostachys cineria, Secureniga leucopyros, Salvadora persica, Zyzyphus oenoplia, Manilkara hexandra) and two invasive species (Opuntia dillenii, Prosopis juliflora) were collected from Bundala National Park and examined for mycorrhizal infection in two different times (wet and dry) of the year. Processing and staining of root samples were carried out using the modified Philips and Heyman (1970) method.

Arbuscular mycorrhizal infections were detected in fine lateral roots of all the studied species except in Manilkara hexandra. Percentage infection of mycorrhizae in dry and wet periods was significantly different. There was an increased mycorrhizal infection in Cassia auriculata, Drypetes sepiaria, Opuntia dillenii and Prosopis juliflora in the dry scason compared to the wet season and this would facilitate the absorption of water and phosphorus by these species and thereby help them to grow and compete with other plant species successfully. A non-cyst forming nematode has been identified in the xylem of fine roots of Manilkara hexandra and this may be the reason for the die-back of mature individuals of the species in the area during the drought periods.

Proceedings of the Ninth Annwal Forestry and Environment Symposium 2003 of the Department of Forestry and Envirommental Science, University of Sri Jayewardenepura, Sri Lanka 